\section{Electronic Waste Management}

G. H. Eduljee and R. M. Harrison (eds), 2nd edn. Royal Society of Chemistry, London, UK, 2020, ISBN 978-1-78801-744-2, 352 pp, £70.00

This collation of chapters around the theme of the management of items of electronic waste gives a global perspective of the main issues that need to be addressed to ensure effective management of these products from initial design through to end-of-life treatment. This updated volume contains new chapters, data and perspectives compared with the first edition. The authors come from a variety of countries and also backgrounds, but most are specialists in hazardous waste management.

Dr Gev Eduljee is currently a non-executive director at Bristol-based consultancy Resource Futures, although he is best known in his previous role as director of external affairs at SUEZ Recycling \& Recovery UK. He has worked in the field of hazardous waste management and as an advisor to the UK Department for Environment, Food and Rural Affairs' (Defra) Advisory Committee on Packaging and Advisory Committee on Hazardous Substances. Professor Roy Harrison is a specialist in environmental health at the University of Birmingham. He is also an advisor at Defra, in air quality, and is on the Department of Health Committee on the Medical Effects of Air Pollutants and its Committee on Toxicity.

The book comprises the following.

Introduction and overview.

Materials used in manufacturing electrical and electronic products.

A circular economy for consumer electronics.

An overview of electronic waste management in the UK.

Management of electronic waste in Africa.

Electronic waste management in the Asia Pacific Region.

Traceability of electronic waste using blockchain technology.

Electronics: a broken story about production and consumption.

The recycling of lithium-ion batteries: current and potential approaches.

Environmentally sustainable solvent-based process chemistry for metals

in circuit boards.

Plastics in electronic waste: results from the PlyCE project.
Despite ever tighter controls being introduced by the European Union (EU) and other Organisation for Economic Co-operation and Development (OECD) countries except the USA covering hazardous waste exports from developed states to less developed states, there is still a huge leakage of waste electrical and electronic equipment (WEEE) and used electrical and electronic equipment (UEEE), intended for further use, with disastrous consequences, socially and environmentally. These aspects are most graphically depicted by Professors Oladele Osibanjo and Margaret Bates in their chapter on Africa, showing the profound damage caused by inappropriate processing of WEEE on the health of the workers, often child labour, and the wider environmental and indirect health impacts suffered by the wider community.

It was reassuring to see that the south-east Asian position was covered, with the past leakage from the Japanese extended producer responsibility (EPR) system, which places responsibility firmly on the producer, namely the consumer as the purchaser of the item. Sadly, however, the consumer having paid for a take-back system where they would be expecting an effective and environmentally sound recovery route to be provided by the reverse-logistics supply chain has failed. However, this issue was not examined by the author, who focused on the legal aspects of the system rather than the potential for leakage, which has probably been minimised since this reviewer was last involved a decade ago.

The PLyCE project takes this book into the vexed issue of plastics in electrical and electronic equipment and how they might be recovered and recycled. PLyCE was a project funded under the EU's Horizon 2020 funding stream. Obviously one of the main problems is the multiplicity of plastics polymers that are currently used for products, albeit for good reasons; EU legislators have chosen not to inhibit the use of new plastics polymer types, while placing restrictions on the older flame-retardant plastic compounds through the Restriction of Hazardous Substances (RoHS) Directive. Although the PLyCE research had not provided any ground-breaking perspectives on the data gathered, the raised profile of this issue does provide important information that can be utilised by WEEE processors and plastics reprocessors.

Jeff Cooper 